\title{
Genetic Diversity Based on Randomly Amplified Polymorphic DNA (RAPD) and Its Relationship with the Performance of Diploid Potato Hybrids
}

\author{
M.M. Paz and R.E. Veilleux \\ Department of Horticulture, Virginia Polytechnic Institute and State University, Blacksburg, VA 24061-0327
}

Additional index words. Genetic distance, anther-derived plants, Solanaceae, Solanum phureja, inbred lines

\begin{abstract}
RAPD analysis was conducted on in vitro plantlets of Solanum phureja Juz. \& Buk. monoploids and diploid heterozygous pollinators. Among 60 decamer primers screened, 11 did not show polymorphism while some primers produced complex banding patterns or faint bands that were difficult to score. Genetic distance estimates were based on 151 polymorphic RAPD markers of 208 bands scored using 33 primers. Simple matching and Jaccard coefficients were calculated to estimate genetic similarity (GS). Genetic distance (GD =1 - GS) among genotypes ranged from 0.0 to 0.664 . Cluster analysis yielded groups of genotypes that were consistent with known genomic compositions or genetic relationships inferred from their pedigree. Field evaluation of $14 \mathrm{~F}_{1}$ families resulting from five $S$. phureja doubled monoploids (DMs) crossed to three heterozygous pollinators (IDs) revealed significant differences in total tuber number, total tuber yield, average tuber mass, and vigor. Total tuber yield per family ranged from 174 to $404 \mathrm{~g}$ per plant and was significantly lower than the control 'Kennebec'. The general combining ability of DM BARD 13-14/202 was superior to other DM parents. Specific combining ability was observed in progeny of AD2-4/3s.8 H ID 4. Among male parents, ID 8 performed better than ID 4 or ID 5. Using simple matching, the largest parental genetic distance was always associated with the highest total tuber yield among progenies of DM parents. A similar trend was obtained using Jaccard coefficients. Based on our results, RAPD markers may facilitate the identification of diverse parents to maximize the expression of heterosis in S. phureja hybrids.
\end{abstract}

The importance of the primitive species Solanum phureja Juz. $\&$ Buk. $(2 n=2 x=24)$ to the improvement of the tetraploid potato $S$. tuberosum L. subsp. tuberosum includes such salient traits as resistance to bacterial wilt, virus resistance, and lack of tuber dormancy (Hawkes and Hjerting, 1989). Lack of tuber dormancy has been significant in the domestication of $S$. phureja, since it can produce more than one crop per year in frost-free valleys at high altitudes (Correll, 1962). This trait would be undesirable, however, in temperate potato production, as it is generally associated with poor tuber storage. Using $S$. phureja in potato improvement requires enhancing its yield components, such as tuber size and tuber set, because the number of tubers per plant tends to be too high in unselected populations (Veilleux, 1990).

Developing highly heterozygous hybrids by crossing clones of diverse parentage may be an essential step to improving yield and quality in $S$. phureja. Broadening the genetic base of breeding populations may be achieved by introducing germplasm of its wild and cultivated relatives. Carroll (1987) reported that $2 x$ hybrids between $S$. phureja and dihaploid $S$. tuberosum showed slightly higheryield and had larger tubers than S. phureja. In tetraploid potato, best breeding results may be obtained by maximizing allelic diversity at as many loci as possible (Mendiburu et al., 1974).

Heterosis or hybrid vigor has been closely associated with heterozygosity at many loci (Mendiburu et al., 1974; Mendoza and Haynes 1974; Stuber, 1994); thus, heterosis may be estimated by divergence for molecular markers between parental genotypes (Hallauer et al., 1988). Restriction fragment-length polymorphism-(RFLP-) based estimation of genetic distance could be used

Received for publication 18 Nov. 1996. Accepted for publication 10 June 1997. We thank Khidir Hilu for help with analysis of genetic relationships by UPGMA and M. Saghai Maroof for help with molecular techniques. This research was supported by grant no. US-2053-91C from BARD, the U.S.-Israel Binational Agricultural Research and Development Fund. The cost of publishing this paper was defrayed in part by the payment of page charges. Under postal regulations, this paper therefore must be hereby marked advertisement solely to indicate this fact. for assigning inbreds to heterotic groups (Melchinger et al., 1992; Smith et al., 1990). Melchinger et al. (1990) reported that genetic distances, calculated from RFLP data as Rogers' distance (Rogers, 1972) between inbred lines of maize, were not adequately associated with heterosis for yield. In tetraploid potato, the significance of maximum heterozygosity in heterosis was reported to depend on the genetic background of the genotype being evaluated (Bonierbale et al., 1993). Another type of DNA marker that has been used to evaluate population differentiation and estimate genetic relationships is the RAPD marker (Jain et al., 1994; Singsit and OziasAkins, 1993; Vaillancourt et al., 1995). The use of RAPD assay to identify cultivars and assign genotypes to heterotic groups is easier and the technique is faster compared to the labor-intensive and time consuming RFLP analysis (Caetano-Anolles et al., 1991; Weising et al., 1991). Comparisons of genetic diversity obtained by RAPD and RFLP analyses have shown that RAPD markers are as reliable as RFLPs to estimate genetic relationships (dos Santos et al., 1994; Hallden et al., 1994; N'Goran et al., 1994).

The broad objectives of this study were to investigate the feasibility of generating potato hybrids based on selection of genetically distant parents as determined by RAPD analysis and to develop high-yielding diploid potato germplasm that may be instrumental in new cultivar development. The specific objectives were to 1) estimate genetic distance using RAPD markers among S. phureja monoploids and diploid heterozygous pollinators (ID lines), 2) evaluate progeny (DM $\times$ ID) performance under field conditions, and 3) investigate the relationship between parental genetic distance and yield or vigor in $F_{1}$ progenies.

\section{Materials and Methods}

Estimating genetic distance among $S$. phureja monoploids and heterozygous pollinators based on RAPD

Plant Material. In vitro plantlets of six anther-derived monoploids of $S$. phureja and four heterozygous pollinators referred to as ID lines were analyzed (Table 1). The ID lines were provided by 
Table 1. Accessions used in the development of diploid potato clones selected for estimating genetic distance.

\begin{tabular}{ll}
\hline \hline Clone designations & Accessions in pedigree \\
\hline BARD 1-3/516 (1x), DM BARD 1-3/516 $(2 x)$ & $p h u$ PI 195191, phu PI 195192 \\
BARD 9-9/203 (1x), DM BARD 9-9/203 $(2 x)$ & $p h u$ PI 225695 \\
BARD 13-14/202 (1x), DM BARD 13-14/202 $(2 x)$ & $p h u$ PI 225681 \\
AD2-4/3s.3 (1x), AD2-4/3s.8 (1x), & $p h u$ PI 225669, phu PI 225682 \\
DM AD2-4/3s.8 (2x), A3P2-6/6n.1 (1x), & \\
DM A3P2-6/6n.1 (2x) & $c h c$ PI 133085, phu PIs 225685, PI 320355, stn PI 195188, tbr US-W1, US-W1711, US- \\
ID4 $(2 x)$, ID5 $(2 x)$ & W7458.1 \\
ID8 $(2 x)$, ID9 $(2 x)$ & $p h u$ PI 283127, stn PIs 195188, 234013, \\
& $t b r$ US-W639, US-W 5004.11, US-W 5278.13, US-W 7360.3, US-W 8152.3, US-W9126.2 \\
\hline
\end{tabular}

Joseph Pavek, USDA-ARS, Aberdeen, Idaho, under the designation $\mathrm{AD} \times 463-5, \mathrm{AD} \times 497-1, \mathrm{AD} \times 881-4$, and AD $\times$ 916-12, corresponding to ID $4,5,8$, and 9 , respectively. They represent complex interspecific hybrids such that ID 4 and ID 5 comprise 1/2 S. stenotomum Juz. \& Buk. (stn), 3/16 S. phureja (phu), 3/16 S. tuberosum (tbr), and 1/8 S. chacoense Bitt. (chc), whereas ID 8 and ID 9 comprise $7 / 16 \mathrm{stn}, 11 / 32 \mathrm{tbr}$, and 7/32 phu. The monoploids and corresponding DMs were derived by anther culture of field selections from an adapted population of $S$. phureja $\times$ S. stenotomum (Haynes, 1972). The BARD clones were independently selected for anther culture competence from a heat-tolerant subpopulation of the original "Haynes' S. phureja." AD2-4/3s.3 and 3s.8 were regenerated by anther culture of a homozygous DM (AD2-4) and would be expected to differ from each other only by possible gametoclonal variation. A3P2-6/6n.1 was derived by anther culture of a hybrid between DM AD3-4 (full sib to AD2-4) and a heterozygous pollinator. In vitro plantlets of these genotypes were maintained on Murashige and Skoog (MS) basal medium (Murashige and Skoog, 1962) for 4 to 5 weeks before DNA extraction.

DNa isolation. Genomic DNA was extracted following the method of Doyle and Doyle (1987) with some modifications. Fresh leaves and stems $(0.3$ to $0.5 \mathrm{~g})$ obtained from in vitro plantlets were ground in liquid nitrogen with a mortar and pestle until a fine powder was obtained. The DNA was isolated using 1 mL CTAB (hexadecyltrimethylammonium bromide) extraction buffer [0.1 м Tris- $\mathrm{HCl}(\mathrm{pH} 8), 1.4 \mathrm{M} \mathrm{NaCl}, 0.02$ м EDTA (pH 8), $2 \% \mathrm{CTAB}$, and $1 \%$ fresh 2-mercaptoethanol], transferred to a $1.5-\mathrm{mL}$ microcentrifuge tube, and incubated in a water bath at $60^{\circ} \mathrm{C}$ for 1 to $2 \mathrm{~h}$. An equal amount of 24 chloroform : 1 isoamyl solution was added to the tube and the contents were mixed and centrifuged for $15 \mathrm{~min}$. The upper aqueous phase was transferred into a new microcentrifuge tube containing $200 \mu \mathrm{L}$ cold isopropanol. The solution was discarded and the DNA pellet was collected and washed twice with cold $75 \%$ ethanol. The DNA was air dried, redissolved in TE $(10 \mathrm{~mm}$ Tris- $\mathrm{HCl}, 1 \mathrm{~mm}$ EDTA) and RNAse $\left(10 \mu \mathrm{g} \cdot \mathrm{mL}^{-1}\right)$. DNA concentration was determined using a minifluorometer (TKO 100; Hoefer Scientific Instruments, San Francisco).

RAPD ANALYSIS. Amplification reactions were done in volumes of $25 \mu \mathrm{L}$ containing $1 \times$ Taq polymerase buffer II (10 mM Tris- $\mathrm{HCl}$, pH 8.3; $50 \mathrm{~mm} \mathrm{KCl}), 2.5$ $\mathrm{mm} \mathrm{MgCl} 2,200 \mu \mathrm{m}$ each of dATP, dCTP, dGTP, and dTTP, and 1.0 unit Taq polymerase. In each of the reaction mixtures, $20 \mathrm{ng}$ genomic DNA was used as template for amplification by polymerase chain re- action (PCR) using 0.6 $\mu \mathrm{M} 10$-mer oligonucleotide. Three priming sets, each consisting of 20 random primers, were tested including OPA, OPC, and OPG (Operon Technologies, Alameda, Calif.). The reaction mix was overlaid with a drop of mineral oil. Thermal cycling conditions consisted of 45 cycles of $1 \mathrm{~min}$ at $94{ }^{\circ} \mathrm{C}$ (denaturation), $1 \mathrm{~min}$ at $36^{\circ} \mathrm{C}$ (annealing), and $2 \mathrm{~min}$ at $72{ }^{\circ} \mathrm{C}$ (primer extension) followed by one cycle of $3 \mathrm{~min}$ at $72^{\circ} \mathrm{C}$ for final extension and a $4{ }^{\circ} \mathrm{C}$ soak until samples were unloaded. All PCR amplifications were carried out in a thermal cycler (model 480; Perkin Elmer, Norwalk, Conn.). Amplified DNA products were analyzed on $1.4 \%$ agarose gel run with Tris-borate-EDTA buffer. The gel was stained with ethidium bromide $(1 \mathrm{mg} / 100 \mathrm{~mL})$ for 10 min and photographed on a UV transilluminator. Reproducibility of results was verified by doing RAPD analysis twice on separate dates, or once but always in conjunction with a positive check, previously characterized. A negative control, which contained all the necessary PCR components except for the template DNA, was included in all PCR runs.

Fig. 1. Agarose-gel electrophoresis of RAPD markers obtained by PCR amplification of genomic DNA obtained from $S$. phureja monoploids and ID lines using decamer primers (left to right) OPA-04, OPA-18 and OPA-19. There are nine lanes for each primer: 1) BARD 9-9/203; 2) AD2-4/3s.3; 3) AD2-4/3s.8; 4) A3P2-6/6n.1; 5) ID 4; 6) ID 5; 7) ID 8; 8) ID 9; 9) control with no DNA. M1 contains EcoR I-Hind III digested lambda DNA and M2 has pBR322 Bst $\mathrm{N} 1$ digest. (Examples of scored bands: band "a" was monomorphic and was not included in calculating genetic distance whereas bands " $b$ " and "c" were polymorphic and were used to estimate genetic distance).

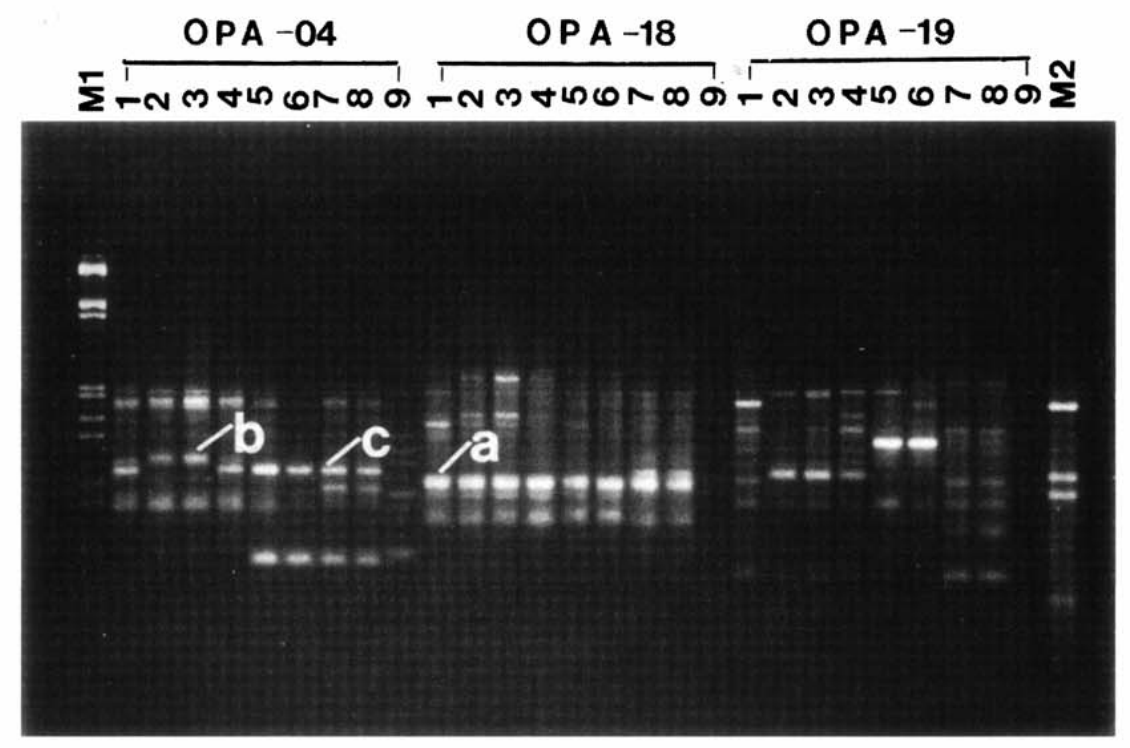


Table 2. Genetic distance (GD) based on RAPD polymorphism among monoploids of $S$. phureja and diploid heterozygous pollinators (ID lines) using Jaccard similarity (regular type) and simple matching coefficients (boldface type).

\begin{tabular}{llcccccccccc}
\hline \hline Genotype & 1 & 2 & 3 & 4 & 5 & 6 & 7 & 8 & 9 \\
\hline 1 & BARD 9-9/203 & & $\mathbf{0 . 5 0 9}$ & $\mathbf{0 . 5 0 9}$ & $\mathbf{0 . 4 2 0}$ & $\mathbf{0 . 5 9 8}$ & $\mathbf{0 . 6 1 9}$ & $\mathbf{0 . 5 8 6}$ & $\mathbf{0 . 5 0 0}$ & $\mathbf{0 . 5 6 9}$ & $\mathbf{0 . 5 7 7}$ \\
2 & AD2-4/3s.3 & 0.377 & & $\mathbf{0 . 0 0 0}$ & $\mathbf{0 . 3 2 1}$ & $\mathbf{0 . 6 2 6}$ & $\mathbf{0 . 6 1 0}$ & $\mathbf{0 . 6 5 9}$ & $\mathbf{0 . 5 9 2}$ & $\mathbf{0 . 6 1 7}$ & $\mathbf{0 . 6 2 5}$ \\
3 & AD2-4/3s.8 & 0.377 & 0.000 & & $\mathbf{0 . 3 2 1}$ & $\mathbf{0 . 6 2 6}$ & $\mathbf{0 . 6 1 0}$ & $\mathbf{0 . 6 5 9}$ & $\mathbf{0 . 5 9 2}$ & $\mathbf{0 . 6 1 7}$ & $\mathbf{0 . 6 2 5}$ \\
4 & A3P2-6/6n.1 & 0.311 & 0.225 & 0.225 & & $\mathbf{0 . 5 9 7}$ & $\mathbf{0 . 5 9 7}$ & $\mathbf{0 . 5 6 6}$ & $\mathbf{0 . 5 0 8}$ & $\mathbf{0 . 5 5 0}$ & $\mathbf{0 . 5 4 7}$ \\
5 & BARD 1-3/516 & 0.429 & 0.463 & 0.463 & 0.456 & & $\mathbf{0 . 5 9 6}$ & $\mathbf{0 . 6 5 5}$ & $\mathbf{0 . 6 1 7}$ & $\mathbf{0 . 6 5 6}$ & $\mathbf{0 . 6 6 4}$ \\
6 & BARD 13-14/202 & 0.477 & 0.470 & 0.470 & 0.483 & 0.407 & & $\mathbf{0 . 5 7 1}$ & $\mathbf{0 . 5 3 6}$ & $\mathbf{0 . 6 4 6}$ & $\mathbf{0 . 6 4 3}$ \\
7 & ID 4 & 0.450 & 0.536 & 0.536 & 0.457 & 0.490 & 0.416 & & $\mathbf{0 . 3 4 0}$ & $\mathbf{0 . 5 2 5}$ & $\mathbf{0 . 5 2 1}$ \\
8 & ID 5 & 0.371 & 0.470 & 0.470 & 0.404 & 0.456 & 0.389 & 0.225 & & $\mathbf{0 . 4 3 9}$ & $\mathbf{0 . 4 3 4}$ \\
9 & ID 8 & 0.464 & 0.523 & 0.523 & 0.470 & 0.531 & 0.537 & 0.401 & 0.331 & \\
10 & ID 9 & 0.470 & 0.530 & 0.530 & 0.464 & 0.537 & 0.530 & 0.404 & 0.325 & 0.007 & $\mathbf{0 . 0 1 1}$ \\
\hline
\end{tabular}

Data ANALYsis. Primers revealing polymorphism were used to determine genetic distance. If a RAPD marker was present in a genotype it was designated 1 , if absent it was given a score of 0 . Pairwise comparisons of genotypes were done to obtain genetic similarity (GS) using simple matching (Sokal and Michener, 1958) and Jaccard similarity coefficients [Jaccard, 1908 (cited by Yu and Nguyen, 1994)]. Genetic distance (GD) among S. phureja monoploids and ID lines was calculated as GD = 1 - GS (Jain et al., 1994). An unweighted pair-group method with arithmetical averages (UPGMA) cluster was constructed using the NTSYS (Applied Statistics, New York) computer program.

Field evaluation of $F_{1}$ hybrids of $S$. phureja DM $x$ ID and the relationship between parental genetic distance and hybrid performance

Plant Material. DMs were generated by leaf disc regeneration in S. phureja monoploid clones based on the methods of M'Ribu and Veilleux (1990) and Hulme et al. (1992). Monoploids detected among anther-derived plants were determined by flow cytometry, then doubled by leaf disc regeneration (Hulme et al., 1992) and verified by another flow cytometric analysis. Subsequently, in vitro microtubers of DMs were generated following the method of Hussey and Stacey (1984) with some modifications. Single nodal cuttings with one leaf were grown on MS basal medium with 5 $\mathrm{mg} \cdot \mathrm{L}^{-1}$ benzyladenine (BA) and $100 \mathrm{mg} \cdot \mathrm{L}^{-1}$ chlorocholine chloride. Cultures were maintained in the dark at room temperature until microtubers were produced. Microtubers of DMs were planted in the greenhouse and resulting plants were maintained under a 16 $\mathrm{h}$ photoperiod. The same procedure was followed with anther donors and diploid ID pollinators. Hybridization was carried out during Spring and Fall 1994. In spring, a set of five $S$. phureja DMs (DM BARD 1-3/516, DM BARD 13-14/202, DM BARD 9-9/203, DM AD2-4/3s.8, and DM A3P2-6/6n.1) was crossed in all possible combinations with a set of ID lines (ID 4, ID 5, ID 8, and ID 9) to generate $F_{1}$ hybrids, and seeds obtained from these crosses were stored at $5{ }^{\circ} \mathrm{C}$ except for ID 9, which did not produce seeds. In August 1994, seeds (100/cross) were treated overnight with $1000 \mu \mathrm{g} \cdot \mathrm{L}^{-1}$ gibberellic acid $\left(\mathrm{GA}_{3}\right)$, then germinated in the greenhouse. Seedlings were transplanted to $25.8-\mathrm{cm}^{2}$ plastic pots and grown in the greenhouse until maturity. Minitubers were harvested in December 1994 and stored at $4{ }^{\circ} \mathrm{C}$ for a minimum of 3 months before planting in the field.

Success of producing $F_{1}$ hybrids in spring was low; hence, more crosses were made in the fall. However, there was not enough time to generate minitubers between seed collection from the fall crosses and field planting. Instead, transplanted seedlings were used for field planting. Seeds (100/cross) were germinated in the greenhouse and transferred individually to cell packs and grown in the greenhouse for 1 month before transplanting to the field.

Field evaluation. Field evaluation was carried out from April to September 1995. The first setup consisted of three replications of five families (DM A3P2-6/6n.1 x ID 4, DM A3P2-6/6n. 1 x ID 5, DM A3P2-6/6n.1 x ID 8, DM AD2-4/3s.8 x ID 5, and DM BARD 9-9/203 $\times$ ID 5) using tubers and seedlings in separate plots as planting materials. Plots of 16 plants were laid out using a stripplot design, with family as the horizontal factor and planting material as the vertical factor. In another evaluation, seedlings of $14 \mathrm{~F}_{1}$ families were planted in a randomized complete block with three replications. 'Kennebec' was used as the check cultivar. Because different seedlings were used in each of the three replications, each family was represented by 48 different genotypes. Established major production, management, and cultural practices for weed and insect control, fertilization, and irrigation for potato were used. The following data were recorded: tuber number per plant, tuber yield per plant, mean tuber mass, vigor (scale of $1=$ high to $4=$ low) at 8 weeks after planting (WAP), and maturity (scale of $1=$ haulm completely dried to $5=$ plants green, still flowering) at 18 WAP. Vigor was scored on an individual plant basis and maturity was scored on a plot basis.

RELATIONSIIIP BETWEEN GENETIC DIVERSITY AND YIELD OR VIGOR. The association between genetic distance of parental genotypes and yield or vigor (based on means of all three replications) in the second evaluation was investigated. Correlation analysis was done.

Fig. 2. Relationships among $S$. phureja monoploids and diploid heterozygous pollinators (ID lines) disclosed by UPGMA cluster analysis of simple matching coefficients based on 151 RAPD markers and 33 primers.

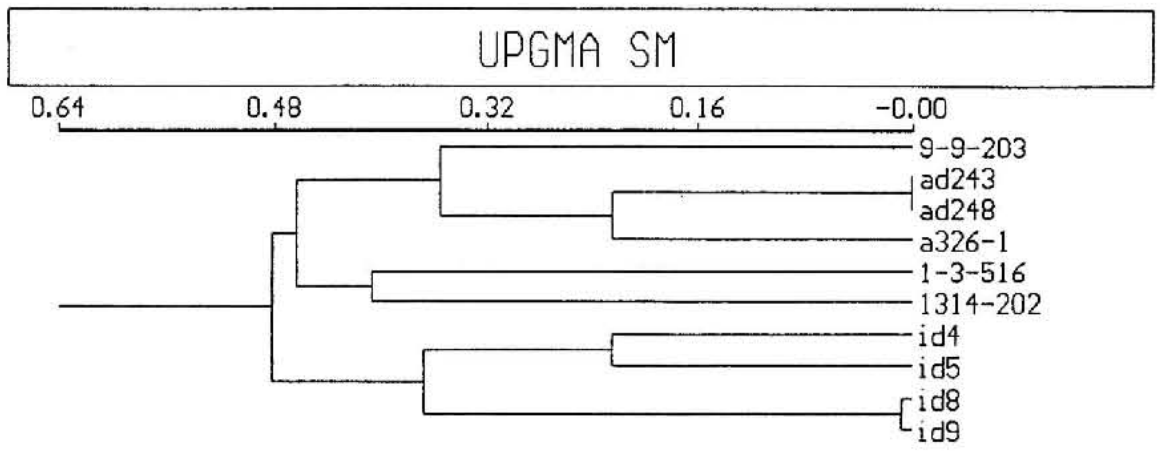


Table 3. Average performance and mean squares from ANOVA of five $F_{1}$ families (DM $\times$ ID) grown from tubers or seedlings.

\begin{tabular}{lccccc}
\hline \hline & \multicolumn{5}{c}{ Performance $^{2}$} \\
\cline { 2 - 6 } Planting material & ATN & ATY $(\mathrm{g})$ & ATM $(\mathrm{g})$ & Vigor & Mat \\
\hline Tuber & $12 \mathrm{a}^{\mathrm{y}}$ & $317 \mathrm{a}$ & $27 \mathrm{a}$ & $2.5 \mathrm{a}$ & $2.6 \mathrm{~b}$ \\
Seedling & $19 \mathrm{a}$ & $249 \mathrm{a}$ & $14 \mathrm{~b}$ & $2.7 \mathrm{a}$ & $3.5 \mathrm{a}$
\end{tabular}

ANOVA

\begin{tabular}{lcccccc} 
Source & df & \multicolumn{5}{c}{ Mean squares } \\
\hline Hybrid (A) & 4 & $1703^{*}$ & $968,052^{\wedge *}$ & $193^{\mathrm{Ns}}$ & $11.9^{*}$ & $1.2^{\mathrm{Ns}}$ \\
Planting material (B) & 1 & $4,883^{\mathrm{Ns}}$ & $294,964^{\mathrm{Ns}}$ & $16,688^{* *}$ & $6.5^{\mathrm{Ns}}$ & $5.0^{*}$ \\
A $\times$ B & 4 & $56^{\mathrm{Ns}}$ & $328,028^{\mathrm{Ns}}$ & $532^{\mathrm{Ns}}$ & $2.5^{\mathrm{Ns}}$ & $0.5^{\mathrm{Ns}}$
\end{tabular}

${ }^{7} \mathrm{ATN}=$ average tuber number; ATY $=$ average tuber yicld; ATM $=$ average tuber mass; Vigor rating: scale of $1=$ high to $4=$ low; Mat = Maturity rating: scale of $1=$ haulm completely dried to $5=$ plants green, still flowering; $F_{1}$ families: DM A3P2-6/6n. $1 \times$ ID 4, DM A3P2-6/6n.1 x ID 5, DM A3P2-6/6n.1 x ID 8, DM AD2-4/3s.8 x ID 5, DM BARD 9-9/203 x ID 5

${ }^{y}$ Means within a column followed by the same letter are not significantly different using SNK at $5 \%$ level.

Ns, ${ }^{* * *}$ Nonsignificant or significant at $P=0.05$ or 0.01 , respectively.

Statistical ANALYSis. All statistical analyses were performed using SAS General Linear Models procedure (SAS Institute, Cary, N.C.).

\section{Results}

\section{Genetic distance among S. phureja monoploids and heterozygous pollinators based on RAPD}

The RAPD products were classified into two types: monomorphic (constant) or polymorphic (variable). From among 60 primers screened, $11(18.3 \%)$ did not show polymorphism, while some primers produced complex banding patterns or faint bands that were difficult to score. A total of 208 bands was scored using 33 primers, and 57 of these were not polymorphic; thus, genetic distance estimates were based on 151 RAPD markers, 39 from 10 OPA primers, 58 from 13 OPC primers, and 54 from 10 OPG primers. A gel electrophoresis of DNA amplified with OPA primers and visualized by staining with ethidium bromide (Fig. 1) showed that PCR products produced by OPA- 18 were monomorphic and, thus, were not included in calculating genetic distance, whereas OPA-4 produced polymorphic bands ( $b$ and $c$ ), which were used to estimate genetic distance.

Simple matching and Jaccard coefficients were used to estimate GS. GD among genotypes ranged from 0.0 between $\mathrm{AD} 2-4 /$ $3 \mathrm{~s} .3$ and AD2-4/3s.8 to 0.664 between BARD 1-3/516 and ID 9 using Jaccard coefficients (Table 2). A similar trend was observed based on simple matching (SM) coefficients: $A D 2-4 / 3 \mathrm{~s} .3$ vs. AD2-4/3s.8, GD $=0.0$; BARD $1-3 / 516$ vs. ID 9, GD $=0.537$ (Table 2). Monoploids of independently selected $S$. phureja (BARD 9-9, 1-3, and 13-14) showed as much diversity within the population as that of $\mathrm{ID}$ pollinators. This underscored the diversity in the adapted population.

Cluster analysis exhibited groupings consistent with known genomic compositions or genetic relationships. Complex diploid

Table 4. Mean squares for vigor, maturity and tuber characters in $14 \mathrm{DM}$ $x$ ID $F_{1}$ families grown from seedlings.

\begin{tabular}{ll}
\hline \hline Trait & Mean square \\
\hline Total number of tubers & $5968.7^{* *}$ \\
Total tuber yield & $2405135.4^{* *}$ \\
Average tuber mass & $37280.9^{* *}$ \\
Vigor & $12.8^{* *}$ \\
Maturity & $1.8^{\text {Ns }}$ \\
\hline
\end{tabular}

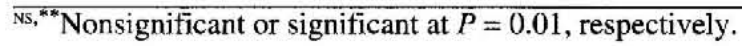

pollinators of similar genomic composition (ID 4 and ID 5) were sorted from those known to have a different genomic composition (ID 8 and ID 9; Fig. 2). AD2-4/3s.3 and AD2-4/3s.8, which are monoploid siblings derived from a homozygous DM, could not be separated. A3P2-6/6n.1 shared a common parent with AD2-4 monoploids and exhibited a lower genetic distance. The fit of the phenogram to the similarity matrix was high with a matrix correlation of $r=0.966$ (Jaccard) and $r=0.945$ (SM).

\section{Field evaluation of $S$. phureja DM x ID $F_{1}$ hybrids and the relationship between parental genetic distance and hybrid performance}

There were no significant differences for average number of tubers, average tuber yield, and mean vigor between similar progenies grown from tubers (tuber families) and seedlings (seedling families) (Table 3). Average tuber mass was significantly higher in tuber families and maturity was delayed in seedling families. No significant interaction effect was observed for any trait (Table 3).

In the seedling population, significant differences among the 14 DM $\times$ ID $F_{1}$ families were observed for total tuber number, total tuber yield, average tuber mass, and vigor (Table 4). Mean tuber yield per plant ranged from 174 to $404 \mathrm{~g}$ for the 14 families. These yields were significantly lower than 'Kennebec' $(1320 \mathrm{~g} /$ plant). However, a bias could have been introduced because Kennebec was tuber propagated. When the yield of each of the 650 genotypes used in the field trial was determined, some plants approached the yield of 'Kennebec' (Fig. 3). The average combining ability of DM BARD 13-14/202 for total tuber yield was superior to that of the other DM parents (Table 5). Specific combining ability was noted in DM AD2-4/3s.8 x ID 4 progeny. Mean yield of progenies of DM BARD 13-14/202 was significantly higher ( $368 \mathrm{~g}$ ) than other DM progenies. However, the number of tubers was also high; hence, the average tuber mass was only $9 \mathrm{~g}$ (Table 5). Among $\mathrm{F}_{1}$ hybrids, a wide range of total number of tubers (13 to 49 ) was observed, whereas 'Kennebec' had an average of 9 tubers. The mean tuber mass of these families varied from 8 to $17 \mathrm{~g} /$ plant compared to 'Kennebec' at $147 \mathrm{~g} /$ tuber.

Among male parents, ID 8 performed better than ID 4 or ID 5 . Average tuber yield of progenies of ID 8 was significantly higher $(338 \mathrm{~g})$ than ID $4(285 \mathrm{~g})$ or ID $5(244 \mathrm{~g})$ (Table 5). The progenies of ID 8 were also the most vigorous. A wide range of total tuber yield and total tuber number was noted for the progenies of each ID pollinator.

Simple correlation of genetic distance with yield among 14 


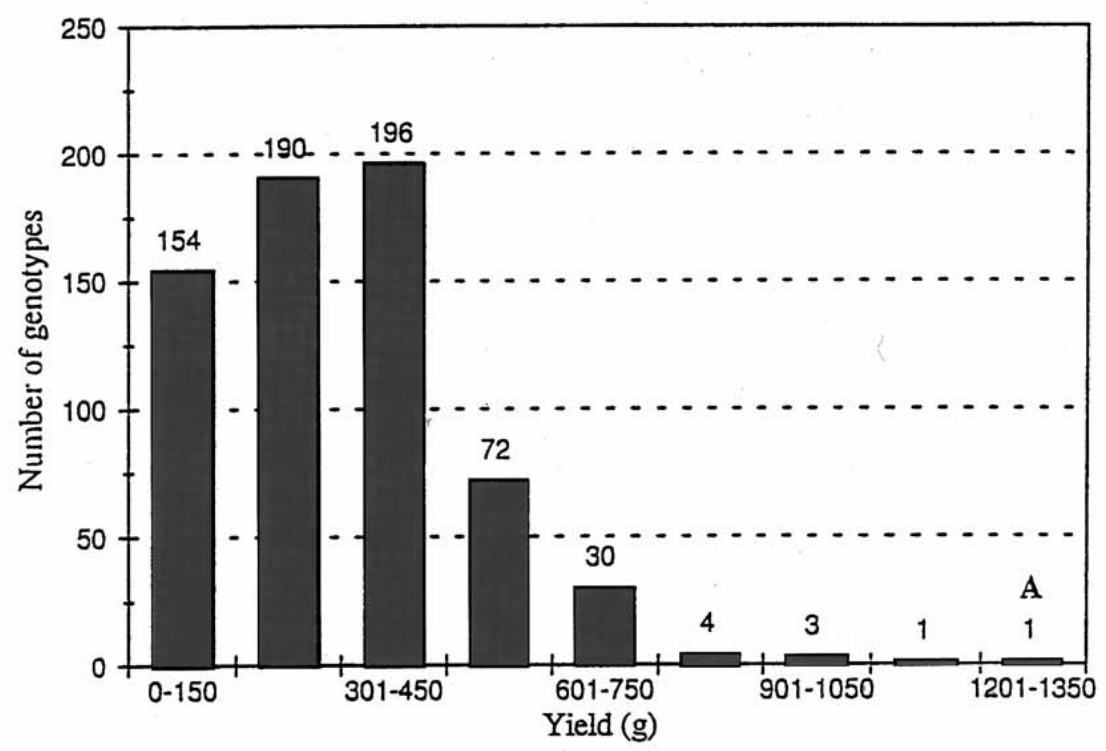

Fig. 3. Distribution of yield among 650 genotypes derived from fourteen DM $\times$ ID $F_{1}$ crosses. The figures above the bars represent the number of genotypes included in each bar; $\mathrm{A}=$ cultivar check 'Kennebec'.

families was not significant. However, perusal of data revealed that, based on simple matching coefficients, the highest total tuber yield was associated with the largest genetic distance among progenies of each DM parent considered separately (Fig. 4). A similar trend was observed in families of DM BARD 1-3/516, DM BARD 13-14/202, and DM AD2-4/3s.8 using Jaccard coefficients. Vigor was not significantly correlated with genetic distance, although a relatively higher plant vigor was coupled with a large genetic distance using simple matching coefficients (Fig. 5). Based on Jaccard coefficients, association between large parental genetic distance and high vigor was attained among the progenies of DM BARD 1-3/516, DM BARD 13-14/202, and DM AD2-4/ 3s.8.

\section{Discussion}

Six monoploids analyzed for RAPD markers were selected from a population of anther-derived monoploids of $S$. phureja based on their ability to generate DMs. The ID lines, which served as paternal genotypes, were selected based on their diverse genetic composition. Comparison between genotypes based on the presence (1) or absence (0) of a RAPD marker produced four possible outcomes as follows: $\mathrm{a}=1,1$; $\mathrm{b}=0,1 ; \mathrm{c}=1,0 ;$ and $\mathrm{d}=0,0$. To obtain a ratio of similarities to total comparisons, simple matching coefficients consider the four outcomes $(a+d / a+b$ $+c+d)$, while Jaccard coefficients do not include absence $\times$ absence comparison $(a / a+b+c)$. Jaccard coefficients were considered more suited than similarity based on absence of character in a study of Sorghum inbred lines (Vierling et al., 1994).

Most primers used in the present study gave good amplification patterns. A bias may have been introduced in assessing GD because monoploids have only one set of chromosomes, whereas the ID lines are highly heterozygous. Since RAPD markers are dominant, homozygous or heterozygous loci in ID lines cannot be differentiated. This may result in underestimating genetic diversity between genotypes. However, our results show that overall banding patterns reflect the natural relationships of the genotypes with no bias in GD estimates. Absence of polymorphism between $\mathrm{AD} 2-4 / 3 \mathrm{~s} .3$ and $\mathrm{AD} 2-4 / 3 \mathrm{~s} .8$ may be attributed to the fact that they were derived from a single DM (homozygous diploid). This also verifies the homozygous nature of the DM parent. Overall, closely related genotypes deduced from their genomic compositions or diploid source are grouped together, which demonstrates that the presence or absence of RAPD markers reflect true genetic relatedness. The advantages of studying DNA polymorphism using in vitro plantlets include the following: 1) RAPD analysis requires only $\approx 0.1$ to $25.0 \mathrm{ng}$ DNA (Demeke et al., 1993; Horn and Rafalski, 1992) and, therefore, small amount of plant tissues; 2) RAPD markers behave as dominant genetic markers (Williams et

Table 5. Performance of progenies of female (DMs) and male (IDs) parents. Numbers in parentheses are family ranges.

\begin{tabular}{|c|c|c|c|c|c|}
\hline Parent & $\begin{array}{c}\text { Families } \\
\text { (no.) }\end{array}$ & $\begin{array}{l}\text { Mean tuber } \\
\text { yield }(\mathrm{g})\end{array}$ & $\begin{array}{c}\text { Mean tuber } \\
\text { no. }\end{array}$ & $\begin{array}{l}\text { Mean tuber } \\
\text { mass }(\mathrm{g})\end{array}$ & Vigor $^{2}$ \\
\hline Female & & & 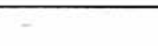 & & \\
\hline DM BARD 1-3/516 & 2 & $\begin{array}{c}299 b^{y} \\
(194-404)\end{array}$ & $\begin{array}{c}28 \mathrm{~b} \\
(18-37)\end{array}$ & $\begin{array}{c}12 \mathrm{~b} \\
(12-13)\end{array}$ & $2.8 \mathrm{a}$ \\
\hline DM BARD 13-14/202 & 3 & $\begin{array}{c}368 \mathrm{a} \\
(357-377)\end{array}$ & $\begin{array}{c}43 \mathrm{a} \\
(34-49)\end{array}$ & $\begin{array}{c}9 c \\
(8-11)\end{array}$ & $2.3 \mathrm{c}$ \\
\hline DM BARD 9-9/203 & 3 & $\begin{array}{c}236 c \\
(193-302)\end{array}$ & $\begin{array}{c}27 \mathrm{~b} \\
(16-36)\end{array}$ & $\begin{array}{c}10 c \\
(8-12)\end{array}$ & $2.2 \mathrm{c}$ \\
\hline DM AD2-4/3s.8 & 3 & $\begin{array}{c}260 \mathrm{bc} \\
(174-321)\end{array}$ & $\begin{array}{c}20 c \\
(13-24)\end{array}$ & $\begin{array}{c}14 \mathrm{ab} \\
(13-15)\end{array}$ & $2.7 \mathrm{ab}$ \\
\hline DM A3P2-6/6n.1 & 3 & $\begin{array}{c}293 \mathrm{~b} \\
(265-326)\end{array}$ & $\begin{array}{c}22 c \\
(19-25)\end{array}$ & $\begin{array}{c}15 \mathrm{a} \\
(14-17)\end{array}$ & $2.6 \mathrm{a}$ \\
\hline \multicolumn{6}{|l|}{ Male } \\
\hline ID 4 & 4 & $\begin{array}{c}285 \mathrm{~b} \\
(197-357)\end{array}$ & $\begin{array}{c}30 \mathrm{~b} \\
(22-46)\end{array}$ & $\begin{array}{c}13 \mathrm{a} \\
(8-15)\end{array}$ & $2.5 \mathrm{~b}$ \\
\hline ID 5 & 5 & $\begin{array}{c}244 c \\
(174-371)\end{array}$ & $\begin{array}{c}20 c \\
(13-34)\end{array}$ & $\begin{array}{c}12 \mathrm{a} \\
(11-17)\end{array}$ & $2.7 \mathrm{a}$ \\
\hline ID 8 & 5 & $\begin{array}{c}338 \mathrm{a} \\
(283-404)\end{array}$ & $\begin{array}{c}34 \mathrm{a} \\
(23-49)\end{array}$ & $\begin{array}{c}12 \mathrm{a} \\
(8-15)\end{array}$ & $2.2 \mathrm{c}$ \\
\hline
\end{tabular}

${ }^{2}$ Vigor rating: scale of $1=$ high to $4=$ low.

y Mean separation within columns by SNK at $P=0.05$. 
al., 1990; Welsh and McClelland, 1990) and, hence, are convenient to use with monoploids, which have only one set of chromosomes; and 3) RAPD assays of monoploid plants allows genotype-based selection before the production of DMs, thus saving time and resources for the plant breeder.

The field studies were conducted on tuber-propagated and seedling populations. A comparison of propagation method for a subset of the same families was made to determine their relative performance. Absence of interaction between propagation method and family (Table 3) was critical for interpreting results of the subsequent experiment using only seedlings but including additional families for which tubers were unavailable. None of the five traits analyzed exhibited such an interaction, a fact that allowed us to interpret the seedling data knowing there was no bias due to propagation method.

Heterosis breeding is a means for improving yield. For improving $S$. phureja, ID lines, which were complex diploid hybrids, were used as sources of germplasm to maximize heterozygosity in progenies. A trend was observed wherein higher yield among the progenies of DM parents was related with increase in parental genetic distance. However, when the ID lines were considered, no
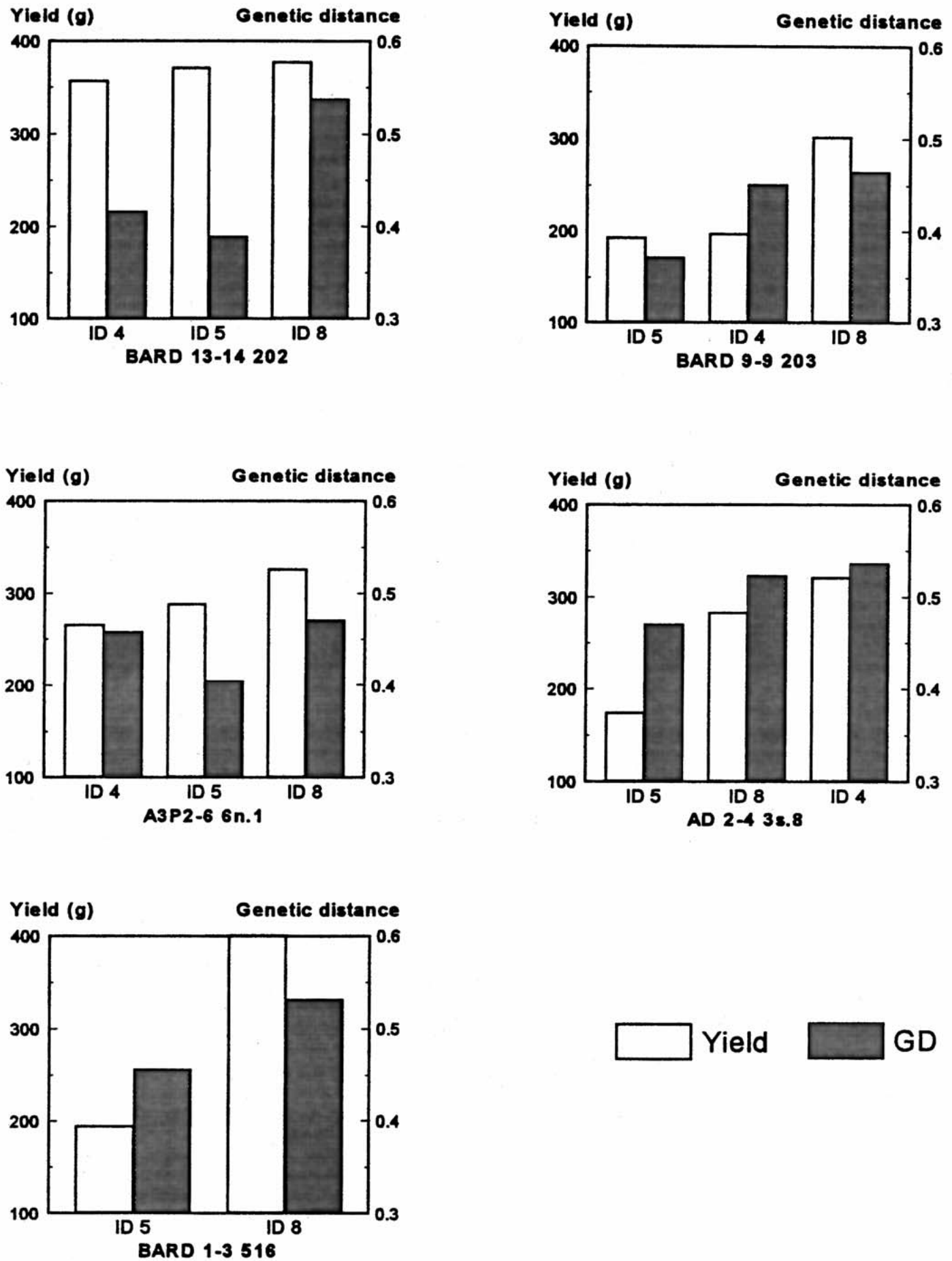

Fig. 4. Relationship between parental genetic distance (GD) based on simple matching coefficients and yield among 14 doubled monoploid $\times$ ID $F_{1}$ crosses with respect to the maternal parent. 
relationship or trend could be ascertained between the yield of the progenies and genetic distance. This may be attributed to the condition that the ID lines were complex hybrids involving unadapted germplasm that may have contributed allelic variance but poor agronomic performance. Hybrid performance between adapted and unadapted clones may be diminished by genes for lack of adaptation (Bonierbale et al., 1993). Although genetic variability may be increased, mean performance may be curtailed, thus hindering selection of good recombinants. Attempts to maximize heterosis in $4 x \times 2 x$ hybrids through introgression of unadapted germplasm has also had mixed results (Bani-Aameur et al., 1991;
Yerk and Peloquin, 1990). The advantages of maximum heterozygosity may be lost if the proportion of unadapted germplasm is too high. For unadapted material, long-term selection efforts to exclude undesirable traits can be used to develop a useful breeding population (Eberhardt, 1971). Selection of maize inbreds for hybridization based on genetic distance differed from the present study due to the general adaptation of germplasm (Smith et al., 1990). If male-fertile DMs of potato become available, a powerful means of selecting parents to generate heterotic combinations would then be possible. Given the germplasm available, the apparent trends observed in this study (Fig. 5) were remarkable.
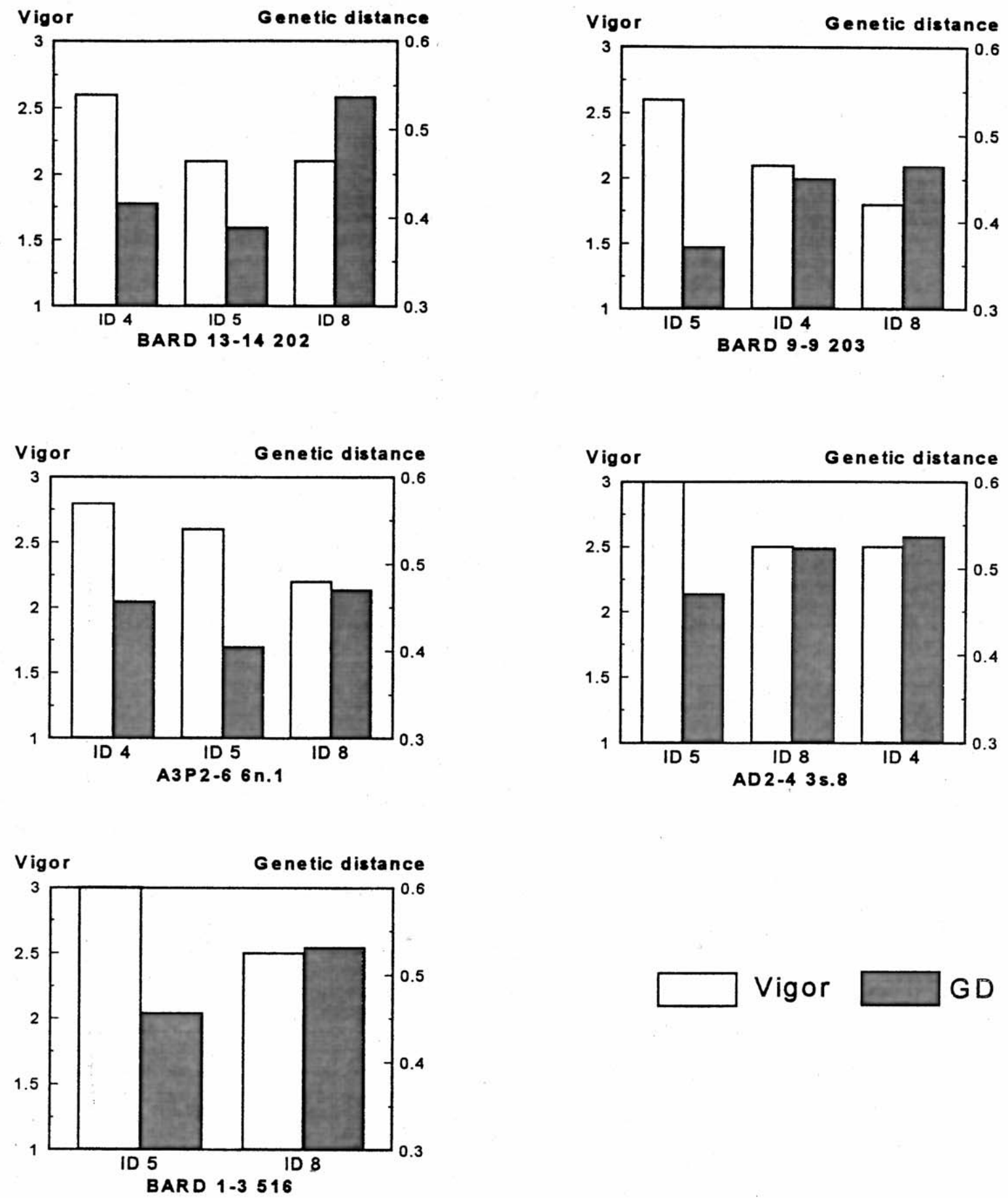

Fig. 5. Relationship between parental genetic distance based on simple matching coefficients and vigor (scale of $1=$ high to $4=$ low) among 14 doubled monoploid $x$ ID $F_{1}$ crosses with respect to the maternal parent. 
To our knowledge this is the first report on the use of DMs to generate hybrids in S. phureja. In a related study, doubled dihaploids $\mathrm{X}$ cultivar crosses have been used to enhance the progeny mean for a dihaploid trait (De'Maine, 1992). Doubled dihaploids, which are more homozygous than their tetraploid parents (De'Maine and Jervis, 1989) but more heterozygous than inbred lines, are also considered potential parents for generating hybrid true potato seed (Clulow et al., 1995). Based on our results, RAPD markers may facilitate the identification of diverse parents to maximize the expression of heterosis in $S$. phureja hybrids.

\section{Literature Cited}

Bani-Aameur, F., F.I. Lauer, R.E. Veilleux, and A. Hilali. 1991. Genomic composition of $4 x$ - $2 x$ potato hybrids: Influence of Solanum chacoense. Genome 34:413-420.

Bonierbale, M.W., R.L. Plaisted, and S.D. Tanksley. 1993. A test of maximum heterozygosity hypothesis using molecular markers in tetraploid potatoes. Theor. Appl. Genet. 86:481-491.

Caetano-Anolles, G., B.J. Bassam, and P.M. Gresshoff. 1991. High resolution DNA amplification fingerprinting using very short arbitrary oligonucleotide primers. Bio/Technology 9:553-557.

Carroll, C.P. 1987. The use of diploid Solanum phureja germplasm, p. 231234. In: J.G. Ellis and D.E. Richardson (eds.). The production of new potato varieties: Technological advances. Cambridge University Press, Cambridge.

Clulow, S.A., J. McNicoll, and J.E. Bradshaw. 1995. Producing commercially attractive, uniform true potato seed progenies: The influence of breeding scheme and parental genotype. Theor. Appl. Genet. 90:519-525.

Correll, D.S. 1962. The potato and its wild relatives. Texas Res. Foundation, Renner, Texas.

De'Maine, M.J. 1992. The use of somatically chromosome-doubled dihaploids in potato breeding and genetic analysis, p. 12-17. In: Proc. Conf. EAPR Breeding and Varietal Assessment, potato section and Eucarpia section. Landerneau, France.

De'Maine M.J. and L. Jervis. 1989. The use of dihaploids in increasing the homozygosity of tetraploid potatoes. Euphytica 44:37-42.

Demeke, T., L.M. Kawchuk, and D.R. Lynch. 1993. Identification of potato cultivars and clonal variants by random amplified polymorphic DNA analysis. Amer. Potato J. 70:561-570.

dos Santos, J.B., J. Neinhuis, P. Skroch, J. Tivang, and M.K. Slocum. 1994. Comparison of RAPD and RFLP genetic markers in determining genetic similarity among Brassica oleracea L. genotypes. Theor. Appl. Genet. 87:909-915.

Doyle, J.J. and J.L. Doyle. 1987. A rapid DNA isolation procedure for small quantities of fresh leaf tissue. Phytochem. Bul. 19:11-15.

Eberhardt, S.A. 1971. Regional maize diallels with US and semi-exotic varieties. Crop Sci. 11:911-914.

Hallauer, A.R., W.A. Russell, and K.R. Lamkey. 1988. Corn breeding, p. 463-564. In: G.F. Sprague and G.W. Dudley (eds.). Corn and corn improvement. 3rd ed. Agron. Monogr. 18. Amer. Soc. Agron., Madison, Wis.

Hallden, C., N.O. Nilsson, I.M. Rading, and T. Sall. 1994. Evaluation of RFLP and RAPD markers in a comparison of Brassica napus breeding lines. Theor. Appl. Genet. 88:123-128.

Hawkes, J.G. and J.P. Hjerting. 1989. The potatoes of Bolivia: Their breeding value and evolutionary relationships. Clarendon Press, Oxford.

Haynes, F.L. 1972. The use of cultivated Solanum species in potato breeding, p. 100-110.In:E.R. French (ed.). Prospects for the potato in the developing world: An international symposium on key problems and potentials for the greater use of the potato in the developing world, 17-29 July. Intl. Potato Ctr., Lima.

Horn, P. and A. Rafalski. 1992. Non-destructive RAPD genetic diagnostics of microspore-derived Brassica embryos. Plant Mol. Biol. Rpt. 10:285293.

Hulme, J.S., E.S. Higgins, and R. Shields. 1992. An efficient genotypeindependent method for regeneration of potato plants from leaf tissue. Plant Cell Tiss. Org. Cult. 31:161-167.

Hussey, G. and N.G. Stacey. 1984. Factors affecting the formation of in vitro tubers of potato (Solanum tuberosum L.). Ann. Bot. 53:565-578.

Jaccard, P. 1908. Nouvelles recherches sur la distribution florale. Bul. Soc. Vaud. Sci. Nat. 44:223-270.

Jain, A., S. Bhatia, S.S. Banga, S. Prakash, and M. Lakshmikumaran. 1994. Potential use of random amplified polymorphic DNA (RAPD) technique to study the genetic diversity in Indian mustard (Brassica juncea) and its relationship to heterosis. Theor. Appl. Genet. 88:116-122.

Melchinger, A.E., M.Lee, K.R.Lamkey, A.R.Hallauer, and W.L. Woodman. 1990. Genetic diversity for restriction fragment length polymorphisms and heterosis for two diallel sets of maize inbreds. Theor. Appl. Genet. 80:488496.

Melchinger, A.E., J. Boppenmaier, B.S. Dhillon, W.G. Pollmer, and R.G. Herrmann. 1992. Genetic diversity for RFLPs in European maize inbreds: II. Relation to performance of hybrids within versus between heterotic groups for forage traits. Theor. Appl. Genet. 84:672-681.

Mendiburu, A.O., S.J. Peloquin, and D.W.S. Mok. 1974. Potato breeding with haploids and $2 n$ gametes, p. 249-258. In: K.J. Kasha (ed.). Haploids in higher plants: Advances and potential. Proc. 1st Intl. Symp., Univ. of Guelph, Guelph, Ontario.

Mendoza, H.A. and F.L. Haynes. 1974. Genetic basis of heterosis for yield in the autotetraploid potato. Theor. Appl. Genet. 45:21-25.

M'Ribu, H.K. and R.E. Veilleux. 1990. Effect of genotype, explant, subculture interval and environmental conditions on regeneration of shoots from in vitro monoploids of a diploid potato species, Solanum phureja Juz \& Buk. Plant Cell. Tiss. Org. Cult. 23:171-179.

Murashige, T. and F. Skoog. 1962. A revised medium for rapid growth and bioassays with tobacco tissue cultures. Physiol. Plant. 15:473-497.

NTSYS. 1988. NTSYS-pc version 1.4. Applied Biostatistics, New York.

N'Goran, J.A.K., V. Laurent, A.M. Risterucci, and C. Lanaud. 1994. Comparative genetic diversity studies of Theobroma cacao L. using RFLP and RAPD markers. Heredity 73:589-597.

Rogers, J.S. 1972. Measures of similarity and genetic distance. Studies in genetics VII. Univ. Texas Publ. 7213:145-153.

Singsit, C. and P. Ozias-Akins. 1993. Genetic variation in monoploids of diploid potatoes and detection of clone-specific random amplified polymorphic DNA markers. Plant Cell Rpt. 12:144-148.

Smith, O.S., J.S.C. Smith, S.L. Bowen, R.A. Tenborg, and S.J. Wall. 1990. Similarities among a group of elite maize inbreds as measured by pedigree, $\mathrm{F}_{1}$ grain yield, grain yield, heterosis, and RFLPs. Theor. Appl. Genet. 80:833-840.

Sokal, R.R. and C.D. Michener. 1958. A statistical method for evaluating systematic relationships. Univ. Kan. Sci. Bul. 38:1409-1438.

Stuber, C.W. 1994. Heterosis in plant breeding, p. 227-251. In: J. Janick (ed.). Plant breeding reviews. vol 12. Wiley, New York.

Vaillancourt, R.E., B.M. Potts, M. Watson, P.W. Volker, G.R. Hodge, J.B. Reid, and A.K. West. 1995. Detection and prediction of heterosis in Eucalyptus globulus. Forest Genet. 2:11-19.

Veilleux, R.E. 1990. Solanum phureja: anther culture and the induction of haploids in a cultivated diploid potato species, p. 530-543. In: Y.P.S. Bajaj (ed.). Haploids in crop improvement I. Springer Verlag, Berlin.

Vierling, R.A., Z. Xiang, C.P. Joshi, M.L. Gilbert, and H.T. Nguyen. 1994. Genetic diversity among elitc Sorghum lines revealed by restriction fragment length polymorphisms and random amplified polymorphic DNAs. Theor. Appl. Genet. 87:816-820.

Weising, K., B. Beyermann, J. Ramser, and G. Kall. 1991. Plant DNA fingerprinting with radioactive and dioxygenated oligonucleotide probes complementary to sample repetitive DNA sequences. Electrophoresis 12:159-169.

Welsh, J. and M. McClelland. 1990. Fingerprinting genomes using PCR with arbitrary primers. Nucleic Acids Res. 18:7213-7218.

Williams, J.G.K., A.R. Kubelik, K.J. Livac, J.A. Rafalski, and S.V. Tingey. 1990. DNA polymorphisms amplified by arbitrary primers are useful as genetic markers. Nucleic Acids Res. 18:6531-6535.

Yerk, G.L. and S.J. Peloquin. 1990. Performance of haploid $\mathrm{x}$ wild species, $2 x$ hybrids (involving five newly evaluated species) in $4 x \times 2 x$ families. Amer. Potato J. 67:405-417

Yu, L.X. and H.T. Nguyen. 1994. Genetic variation detected with RAPD markers among upland and lowland rice cultivars (Oryza sativa $\mathrm{L}$.). Theor Appl. Genet. 87:668-672. 